the condition generally had been progressively worse ever since. She was treated at Harrogate, Buxton, and here by diets, douches, massage, electricity, ointments, splints, and by guaiacol, salicylates, and many other drugs. Beyond a temporary improvement from thiocol and from local counter-irritation the result was nil.

When she came to me she walked with a limp, was poorly nourished, asthenic, and despondent. The hands and feet were cold, the hands being clammy and cyanosed as in Raynaud's disease. There was an offensive odour of the skin, and pigmentation of the eyelids and temples. The weight was $8 \mathrm{st}$. $4 \mathrm{lb}$. There were pain and tenderness, with effusion and periarticular thickening of some of the metatarso-phalangeal joints, of both wrist, elbow, and kneejoints. Pain in the temporo-maxillary and hip-joints, and pain and swelling over the cervical and upper dorsal vertebræ, and of both shoulder-joints. There was creaking of most of the joints and along the extensor tendons of the forearms. The right elbow was immobile, and there was very little movement of the wrist-joints and limited movement of the spine. There were no Heberden's nodes or osteophytic outgrowths, and no ulnar deviation of the fingers. There was anorexia with a furred tongue, but no vomiting, and the bowels acted only with purgatives. The fxces showed a few undigested muscle fibres under the microscope, but were otherwise normal. The total urine in 24 hours was 42 ounces, there was no albumin or sugar, the chlorides were about normal, and there was a trace of indican. A diagnosis of rheumatoid arthritis was made.

I searched for every possible source of sepsis but found none. Nor did a dentist who examined her teeth, or a laryngologist and rhinologist who examined her nose and throat. A gynæcologist also investigated her and found no sign of tubercle or gonococcus infeetion, but only a simple endometritis, for which the uterus and cervix were curetted and otherwise treated. During the year which she spent under my care I treated her with thyroid gland, paraffin, potassium iodide, and many other drugs, with iontophoresis and passive congestion to the joints, and with electricity and massage, and with various diets, the result being nit. I then persuaded her to fast for 14 days. During the fast she was mostly in bed, drank hot water every three hours, and had a soap-and-water enema every other day. She felt weak but never hungry. The result was striking. On the fourtb day pains began to diminish, and on the eighth day there was no longer pain in any joint, and swelling and effusion continued to diminish until the end of the fast. On the third day after beginning to eat the joints began to swell and be painful, and in a few days became as bad as ever. While under my care she had three mild attauks of cystitis. A coliform bacillus was isolated from the urine.

During three months she was treated by a vaccine made from this bacillus. The joints reacted to this vaccine, and there was a slight but transient improvement on the whole. While under my care there was never any pyrexia, the temperature being usually $96 \cdot 4^{\circ} \mathrm{F}$. in the mouth. The joints were always worse in hot weather. Five grains of carmine by mouth in a cachet appeared in the stools from 18 to 85 hours later. Last October I X-rayed her after a meal containing $z$ ii of bismuth oxychloride, and found that the greater curvature of the stomach was $1 \frac{1}{2}$ inches below the umbilicus, and that after 7 hours the bismuth was all in the small intestine, after 17 hours all in the ascending colon, and after $46 \frac{1}{2}$ hours some in the dropped transverse colon and some in the pelvic colon. Between the last two observations a black motion was passed. All the observations were made with the patient in the standing posture.

Since all the evidence now seemed to incriminate the intestine, and since the disease was slowly progressing, I sent her into Guy's Hospital on Dec. 15th last under the care of Mr. W. Arbuthnot Lane. Here Dr. A. C. Jordan X-rayed her in a recumbent posture after a meal containing $\xi$ vi of bismuth oxychloride, and the following observations were recorded :-

After eight hours : Terminal coil of ileum hypertrophied. Transverse colon greatly dropped. After this the bowels acted. After 32 hours : All the bismuth in the cæcum, ascending, and transverse colon. After 56 hours: Same as the last, also some bismuth in the pelvic colon. After 104 hours : Traces of bismuth in the cæcum and ascending colon, the remainder in the transverse, descending, and pelvic colon.

On Jan. 3rd Mr. Lane performed the following operation :-

As soon as the patient was under the anæsthetic, continuous infusion with normal saline was started. An incision about continuous infusion made through the left rectus close to the middle line, and the peritoneal cavity opened. A marked kinking was found at the lower end of the ileum, about three inches from its junction with the crecum, due to an adventitious mesentery attached to the bowel some distance from the true mesentery, and behind to the root of the mesentery The duodenum was large, but not so noticeably so as in some cases. The ileum above the kink was clamped, tied, and divided, the ends being cauterised. The distal end was invaginated by pursestring sutures of thread. The lower part of the pelvic colon was brought out of the wound, clamped by intestinal forceps, and an end to side anastomosis made between the ileum and pelvic colon. Above the anastomosis the pelvic mesocolon was shortened by means of a thread suture so as to exaggerate the "last kink" and to prevent regurgitation of fæces from the rectum into the colon. Then the hole left between the mesentery and the pelvic mesocolon was closed with a continuous suture. A rubber tube was passed up the rectum and guided from the inside through the opening into the ileum and passed up the ileum, a quantity of paraffin being injected through the tube. The abdominal wall was closed in layers. A hot fomentation covering the whole of 48 hours the rectal tube was removed.

Four days after the operation all the joints began to improve, and three weeks later the general condition began to improve, and improvement since has been uninterrupted. Her present condition is : Weight $9 \mathrm{st} .7 \mathrm{lb}$. ; the appetite is good, the tongue clean, and she is cheerful and well nourished, and the hands have lost their former Raynaudlike appearance, and the offensive odour of the skin is much less. The gynæcologist referred to above has recently seen the patient and writes to me about the "immense improvement in the appearance and general condition of the patient after the operation." Beyond some pain in the right elbow, there is no longer pain or tenderness in any joint, and there is a slightly increased range of movement in all joints, the right elbow showing some movement. There is still much periarticular thickening and some bony grating of the left. shoulder-joint, but no effusion into any joint. There is some "thumping of the heart when fatigued," and a faint mitral systolic murmur can now be heard, but there is no enlargement of the heart. There is no lencorrhoa, no induration of the left breast, and menstruation occurs every four or five weeks. The first menstruation after the operation was "rather bad, not. anything to speak of since." She is swallowing enough paraffin to ensure defæcation twice a day. Carmine taken by the mouth appears in the stool 16 to 24 hours later. The fæces are formed and of normal appearance. Under the microscope there is a little mucus intimately mixed with the fæces, and a few undigested muscle fibres. The urine contains a very faint trace of indican, the chlorides are abundant, and it is slightly turbid from the same coliform bacillus from which the vaccine was made.

In conclusion, I should like to express my appreciation of the work of Mr. Lane and Dr. Jordan in this case.

I am, Sir, yours faithfully,

Waterloo, Liverpool, April 24th, 1913. SYDNEY WHITAKER。

\section{THE TREATMENT OF ARTERIO-SCLEROSIS AND HIGH TENSION.}

To the Editor of $\mathrm{TH} \mathbf{E}$ L $\triangle$ N C E T.

SIR,-A recent discussion on the above subject at the Medical Society of London raises a question which you may think worth an airing. Those who were present at the meeting on April 28th, to which I refer, were provided with many instructive items; but the remarks of all the speakers I heard were directed to the treatment of these ailments from the date at which they become productive of symptoms. I submit that treatment begun at this stage is begun in most cases at least ten years too late to be remedial, however precious it may be for palliative purposes. It is the generally received opinion that arterio-sclerosis and high tension are not usually vices inherent in the circulatory system, but are the outcome of composite metabolic faults operating over a long period of years; and further, that they are themselves no more than secondary manifestations indicative of permanent mischief already accrued to vital organs, notably the kidneys. Your readers will recognise in the following synopsis a common type of case which matures to symptoms between the fifties and sixties. Chapter I.: Chronic metabolic poisoning; growing blood pressure ; no arterio-sclerosis. (Curable.) Chapter II. Chronic metabolic poisoning; high blood pressure; commencing arterio-sclerosis; no symptoms. (Less curable.) Chapter III. : Chronic metabolic poisoning; high blood pressure; arterio-sclerosis; symptoms. (Incurable; to be palliated only.) 
- It appears, then, that the bulk of the patients whom we treat for arterio-sclerosis and high tension have already passed through two preliminary phases, each of some years' duration, phases during which it might be claimed with some justice that a cure can be found for the ingravescent fault. But how are these phases to be detected in time? It seems to me that there is only one answer to this question. We cannot cure the faults which underlie arterio-sclerosis and high tension unless we can persuade the public that periodical medical examinations during periods of health are as vital to their bodily security as are periodical visits to the dentist to the welfare of their teeth. At present they come to us to be cured at a stage when a cure, too often, is already past hoping for, and I venture to suggest that we have submitted too readily to the popular assumption that we have cures at our command for these and other slow fruitions of insidious diseases. There is a glamour about the word "cure" which fascinates the layman; and for ourselves a flattering echo lurks about it which tempts acquiescence in the claims the public makes on our behalf. But surely it would be plainer dealing if we said outright: "Come to us in time and we can do a good deal, by commonsense advice on diet and hygiene, to cure you in advance of many of the ills which may be threatening you; but we cannot re-make organs already damaged past repair."

If there be truth in what I say it follows that people should be brought to see that periodical visits to the ductor for a general overhaul and advice constitute an insurance against a good many preventable diseases. It is an invidious necessity that their education in this particular should fall upon ourselves, but no one else can take the matter off our hands. No doubt cynics will accuse us of self-seeking, though I think we should gain more in satisfaction than in money in the long run. In any case we could afford to put up with the jeer till it died a natural death if, as seems to me to be axiomatic, arterio-sclerosis and its congeners-high blood pressure and chronic interstitial nephritis-can only be cured by preventing them.

I am, Sir, yours faithfully,

Devonshire-place, W., April 30th, 1913. WILLIAM P. S. BRANSON.

\section{ENDEMIC GOITRE: THE CAUSATIVE FACTOR.}

To the Editor of THE LANCET.

SIR,-A critical study of the investigations, deductions, and conclusions of Major R. McCarrison relating to Endemic Goitre ${ }^{1}$ will show that the "toxic agent" has escaped his observation. For example, a study of the various probable causes, such as the influence of the soil, the chemical substances in water, together with the experimental production of the disease in man, all go to show that there is some radical defect in the hypothesis that endemic goitre is due to a "living excitant." That there is a causative factor cannot be denied, but it cannot be detected in humid soil or in arid areas. Neither can it be charged to the presence of inorganic substances in water, because it is known that endemic goitre prevails in communities where rain-water exclusively is used, and also where melted snow furnishes the supply. Numerous authors are quoted to confirm the theories advanced, that of Baillarger (1873) as follows: "Chemical analyses do not support the view that goitre is due to the presence of chemical saits in the water."

The "lime and magnesium theory" is dismissed as untenable, simply because the investigators have failed to demonstrate that the presence of either one or both exercises any influence whatever upon the production of the disease, and I shall not be anticipating my conclusions relating to the influence of lime and magnesium when I give consent to the proposition that the mineral constituents of the water may be entirely without effect; that, however, does not exclude the possibility of these minerals becoming the causative factor in the production of the disease, since we have to deal with both in the dietary. The question is, How is it possible to connect the influence of the water or the soluble substances which it contains with the appearance of the disease in endemic form?

To clear up this question let us take the statistics given on p. 221 from seven villages in the Gilgit Fan, containing all told a population of 2192 . Water was supplied to these villages in succession, and the prevalence of goitre as given in the table shows a romarkable increase as the watersupply advances. In the first village, with 93 inhabitants, the per centage of population affected is 11.8 ; in the fourth village, with 718 inhabitants, the percentage of goitrous population is 20 ; while in the seventh village, with 128 inhabitants, the goitrous population is 45.6 per cent. Now, while it seems probable that the water in this section or some substance dissolved in it was responsible for the rapid increase of goitrous population, it does not entirely con. vince, but we must bear in mind that under these circum. stances the presence of nitrites is almost certain. This is better shown in Gaylord's observations on fish, also quoted, that fish in the water above the tanks were goitre free, while the percentage of goitrous fish in the first, second, third, and fourth tanks was $3,8,45$, and 84 respectively. In explaining his theory to account for the rapid increase of goitre in the successive tanks, Major McCarrison traces it to their habit of "nosing about the walls and in the bottom of the tanks," which are precisely the places where suspended matter deposits itself in the form of remnants of food, forming a nidus for the growth of numerous bacteria and animalculæ. Further, he holds that it is in these deposits that we must look for the cause of the disease, since it existed neither in the water flowing into the first tank, nor from that escaping in the last, in sufficient quantity to cause goitre.

Evidence of a like character is to be found in the observations of Dr. Marine and Dr. Lenhart relating to the presence of goitre in artificially bred trout, but in this case the water in which these brook trout develop goitre most actively was not allowed to come in contact with the soil, and thus we have a demonstration that the presence of inorganic matter in the water had nothing to do with endemic goitre. A like conclusion is warranted in the case of goitre in man artificially produced in no less than eight experiments, the former conclusion being confirmed by the statement that " all of the cases of artificially produced goitre were rapidly cured by the administration of thymol." At this point should be mentioned the experimental investigations of $M$. Trillat, as published in THE LANCET of Dec. 14th, 1912, p. 1670. M. 'Trillat found that " certain putrid gases dissolved in water exercised a favourable influence on microbes contained in it," and further, that these volatile, alkaline substances exerted an activating effect on germs. Even so small a percentage of ammonia in the air as " 1 to $5,000,000$ exerted a favourable influence, although much less than that of the amides of the fatty series produced in putrefaction." Now this evidence has a direct bearing upon the present question because of the fact that while decomposition of th fatty series is augmented by the presence of nitrites, there is a marked derangement of the proteid metabolism and thus the susceptibility to various organisms, pathogenic and non-pathogenic, is increased.

To the impartial student a careful examination of these records will show beyond question that the normal constituents of water are not responsible for goitre. They show, further, that whatever infuence may have been produced upon the thyroid gland was due to the presence of nitrites, because we know that in ordinary cases of indigestion we have disordered proteid metabolism, together with the pro. duction of amides-as a consequence, a multiplicity of acute, subacute, and chronic disorders. It remains to be demon. strated, however, that these intestinal disorders may lead to goitre, as well as to other disorders when the conditions are favourable. It would not be profitable to discuss here various questions relating to the influence of climate, hereditary tendencies, environrnent, \&c., becanse we can locate and identify the causative factor when we understand the nature of the inorganic chemical changes which take place as a result of chemical deviations in the body fluids (blood and lymph) and tissues. In the accompanying tabulation, showing mineral depletion from a "eracker" diet, I have only changed the data by adding the equivalent of the metric figures in grains, using 15.43 as the equivalent of one gramme, so that the figures are approximately correct for two decimal places.

The following quotation from the authors gives a very complete description of the experiment. The daily diet consisted of 450 grammes of the same lot of soda crackers as were used in the first and second experiments, with an 